\title{
TEORIA POLÍTICA: UM BALANÇO PROVISÓRIO
}

\author{
Javier Amadeo
}

\begin{abstract}
RESUMO
Um pressuposto fundamental para o desenvolvimento de uma Teoria Política vigorosa é a possibilidade de proporcionar uma inteligibilidade reflexiva de seu próprio desenvolvimento, relacionando, para isto, explicações que lhe são intrínsecas com uma história externa de seus exitos e fracassos. O objetivo do presente trabalho é realizar um balanço provisório dos desenvolvimentos, problemas e desafios da Teoria Politica nas últimas décadas, tentando analisar esses desenvolvimentos como parte de uma história intelectual mais ampla. Para isso, é necessário retroceder à década de 1960, quando existia a percepção do declínio da reflexão teórica; a partir desse momento parece haver um surpreendente "ressurgimento" da Teoria Política. O texto busca sugerir uma reconstrução da Teoria Política das últimas décadas a partir da hipótese de uma reconfiguração fundamental de seus pressupostos. Um dos elementos centrais desta reconfiguração tem sido a progressiva divisão entre elementos filosóficos e históricos da construção teórica que nesta reconstrução estão representados por duas das correntes teóricas surgidas na década de 1970: a Teoria Política normativa e a história do pensamento politico. Essa narrativa, portanto, propõe uma reconstrução de um ponto de vista particular e enfatiza determinados aspectos da elaboração teórica das décadas passadas, subtraindo análises de autores e formulações de importância substantiva que, no entanto, não serão consideradas.
\end{abstract}

PALAVRAS-CHAVE: Teoria Política; Ciência Política; História do Pensamento Político; teoria normativa.

\section{INTRODUÇÃO}

Como afirma Terence Ball, as periódicas reavaliações e reconsiderações do que herdamos dos autores que nos antecederam são empreendidas, e não podia ser de outra forma, sob a perspectiva de nossos problemas e circunstâncias (BALL, 2004). Um exame da Teoria Política no presente só poderia começar fazendo uma análise dos desenvolvimentos nas décadas anteriores, para entender como se chegou a este presente.

Um pressuposto fundamental para o desenvolvimento de uma Teoria Política vigorosa é a possibilidade de proporcionar uma inteligibilidade reflexiva de seu próprio desenvolvimento, relacionando, para isto, explicações intrínsecas de seus êxitos ou fracassos com uma história externa que a complemente. O objetivo do presente trabalho é realizar um balanço provisório dos desenvolvimentos, problemas e desafios da Teoria Política nas últimas décadas. Para isso é necessário retroceder até a década de 1960, quando existia uma percepção generalizada sobre a decadência desta reflexão teórica; a partir desse momento se produziu um surpreendente "ressurgimento", ou reconfiguração, da Teoria Política. Esse "ressur- gimento" trouxe novos temas, problemáticas diversas e abordagens originais, no entanto essa prosperidade pode pressagiar limites e problemas que devem ser colocados em questão.

Dessa forma, o texto busca propor uma reconstrução da Teoria Política das últimas décadas com base na hipótese de uma reconfiguração fundamental dos pressupostos a partir dos quais ela era elaborada. Um dos elementos centrais desta reconfiguração tem sido a progressiva divisão entre elementos filosóficos e históricos da construção teórica que nesta reconstrução estão representados por duas das correntes teóricas surgidas na década de 1970: a Teoria Política normativa, formulada por John Rawls e a enorme literatura surgida a partir da publicação de Uma teoria da justiça (1971), e a história do pensamento político desenvolvida - no mesmo período - pelos autores da Escola de Cambridge, particularmente Quentin Skinner e J. G. A. Pocock. Esta narrativa, portanto, propõe uma reconstrução de um ponto de vista particular e enfatiza determinados aspectos da elaboração teórica das décadas passadas subtraindo a análise de autores e formulações de importância substantiva que, no entanto, não serão consideradas.

Rev. Sociol. Polít., Curitiba, v. 19, n. 39, p. 17-34, jun. 2011 


\section{A TEORIA POLÍTICA FACE À REVOLUÇÃO COMPORTAMENTALISTA}

As primeiras décadas do século XX e os anos de pós-guerra constituíram um período fundamental para entender o estabelecimento da Ciência Política como disciplina acadêmica. Durante esse período se construiu o consenso dominante - tanto do ponto de vista teórico como do ponto de vista prático-institucional - sobre o estatuto da disciplina, seus objetivos, escopo e fundamentalmente sobre seu método. Uma das conseqüências mais importantes foi o estabelecimento de uma dicotomia fundamental entre Teoria Política, entendida como a história do pensamento político, e Ciência Política, entendida como análise empírica das instituições políticas. Como sucede com a construção de todas as "histórias oficiais", o resultado final tendeu a naturalizar uma determinada concepção vencedora frente às alternativas derrotadas nessa "luta pelo poder"1.

Como afirma Gabriel Almond (1996), durante o período pós-guerra houve um rápido crescimento no processo de institucionalização e profissionalização da Ciência Política, em grande parte como resultado da experiência interdisciplinar do período de guerra. Os currículos de Ciência Política e os departamentos nas universidades se expandiram rapidamente em resposta a uma nova concepção da disciplina e à ampliação da educação superior. $\mathrm{O}$ estudo das relações internacionais, estimulado pelo novo papel dos Estados Unidos como potência hegemônica, passou a ocupar um lugar central nos novos institutos de pesquisa das principais universidades norte-americanas, como Yale, Princeton, Columbia e Harvard.

Novas especialidades como estudos de segurança, economia política internacional, opinião pública e estudos culturais foram incorporados às antigas sub-especialidades. O novo cenário internacional de pós-guerra levou os Estados Unidos, de forma similar ao que aconteceu com as antigas potências hegemônicas, a investir na formação de especialistas para analisar os processos e problemas do desenvolvimento dos países em desenvolvimento ou países surgidos do processo

\footnotetext{
1 Para uma análise sugestiva do estudo da política no século XIX e algumas das conseqüências de sua institucionalização no século seguinte, ver Collini, Winch e
} Burrow (1987). de descolonização na Ásia, África, Oriente Médio e, especialmente, na América Latina. Os departamentos de Ciência Política, e os incipientes programas de relações internacionais, expandiram-se rapidamente para adequar-se a essas novas necessidades e especialidades. Esses novos temas e problemas foram acompanhados pelo surgimento de uma nova perspectiva analítica para a Ciência Política ${ }^{2}$.

Na primeira década do período pós-guerra, Talcott Parsons e outros autores da mesma orientação teórica desenvolveram o conceito de sistema para comparar tipos diferentes de sociedades e instituições, partindo do trabalho de teóricos como Weber e Durkheim. Com base nessa e em outras fontes, David Easton introduziu de forma original o conceito de sistema na Ciência Política (EASTON, 1953; 1965).

Easton, provavelmente o autor mais importante desta primeira geração de teóricos comportamentalistas, problematizou a enorme produção de dados quantitativos e qualitativos gerados pela ciência social da década de 1950, e ao mesmo tempo detectou a ausência de uma teoria sistemática para avaliar esses dados. Como conseqüência, era necessário o desenvolvimento de uma ciência própria para os estudos políticos que permitisse a produção de "um conhecimento universal e confiável sobre os fenômenos sociais"; "o propósito de um procedimento de acordo a regras científicas é fazer possível a descoberta de uma teoria altamente generalizável" (EASTON, 1953, p. 65-66). Na visão de Easton, uma "teoria geral" da Ciência Política deveria consistir em um sistema dedutivo de pensamento, com um número limitado de postulados, como pressupostos e axiomas, um corpo de generalizações empiricamente validadas que poderiam ser deduzido em

\footnotetext{
2 Três instituições norte-americanas foram especialmente importantes durante o período em questão. Em primeiro lugar a Universidade de Michigan, e seu Instituto de Pesquisa Social, influenciado por investigações no campo da psicologia social; em segundo lugar, o Departamento de Pesquisa Social Aplicada de Columbia, fundado pelos sociólogos Paul Lazarsfeld e Robert Merton; por último, o Centro de Pesquisa de Opinião Nacional da Universidade de Chicago, dirigida nos seus primeiros anos pelo sociólogo Cyde Hart. Estas instituições produziram e difundiram a literatura e formaram os pesquisadores que contribuíram de forma substancial para a "revolução comportamentalista" (ALMOND, 1996, p. 70).
} 
uma ordem descendente para especificar e prover explicações causais preditivas do comportamento político (BEVIR, 2006, p. 592).

O livro de Easton, O sistema político (1953), insistia no fracasso da Ciência Política da década de 1950 para construir teorias coerentes sobre o fenômeno político, e para desenvolver técnicas para coleta e análise de dados, com as quais fosse possível construir essas teorias. A definição mais amplamente conhecida e usada sobre a política foi colocada por Easton na sua definição de sistema político como a "distribuição autorizada de valores na sociedade". Essa definição colocava para os pesquisadores uma orientação fundamental para delimitar o conteúdo da Ciência Política.

Dessa forma surgia uma nova Ciência Política, baseada em uma epistemologia positivista ${ }^{3}$, que buscava analisar a partir de métodos estadísticos os processos de modernização e democratização e o desempenho governamental. Para estes autores era possível obter, a partir destes critérios científicos, um progresso significativo na compreensão do funcionamento dos grupos de interesse e no fenômeno do corporativismo, assim como uma melhor apreciação do papel fundamental dos partidos políticos no processo democrático (ALMOND, 1996, p. 72-73; cf. também GUNNELL, 1983; BEVIR, 2006; BALL, 2007).

Como afirma Terence Ball, uma das conseqüências mais importantes da revolução comportamentalista das décadas de 1950 e 1960 foi o estabelecimento de uma separação clara e irreconciliável entre "ciência" política e o estudo do pensamento político, e como conseqüência uma desvalorização da segunda ${ }^{4}$. Para construir uma abordagem verdadeiramente científica da política

3 Exploraremos esse ponto com mais detalhe na próxima seção.

4 A primeira geração de cientistas políticos influenciados pelo comportamentalismo - David Easton, Robert Dahl e David Truman - começou como estudantes de Teoria Política, e alguns dos primeiros trabalhos analisavam pensadores importantes da tradição ocidental do pensamento político. Textos importantes como: A History of Political Theories de William Dunning, Growth of Political Thought de Charles McIlwain e especialmente $A$ History of Political Thought de George Sabine foram as fontes intelectuais de todos esses cientistas políticos. No entanto, a necessidade de estabelecer critérios científicos para a análise dos fenômenos políticos levou esses autores a rejeitar o suposto historicismo anacrônico de seus antecessores. era necessário deixar de lado a preocupação com o pensamento político pré-científico. A revolução comportamentalista, dessa forma, estabeleceu uma linha de demarcação entre o estudo "científico" do comportamento político e o estudo "histórico" do pensamento político ${ }^{5} \mathrm{e}$, assim, pensamento e ação eram separados analiticamente e não existia nenhuma relação entre ambos. David Easton, em O sistema político, criticava a abordagem preponderante da política afirmando que "A Teoria Política hoje está interessada fundamentalmente na história das idéias" (BALL, 2001, p. 108-9; sem grifos no original).

Essa separação entre estudo científico da política e uma perspectiva filosófica ou histórica, como campos separados, levou a um clima de época marcadamente hostil em relação à teoria e à filosofia política. Autores de tendências teóricas e posições políticas diferentes pareciam concordar em um diagnóstico comum, a frase de Peter Laslett em sua introdução à Philosophy, Politics and Society (1956) talvez sintetizasse da melhor maneira esse clima de época: "no momento, de qualquer maneira, a filosofia política está morta" (LASLETT, 1956, p. vii; sem grifos no original). Leo Strauss, por sua vez filósofo político de tendência conservadora, com formação na

5 "If we were to model the history of political science in ages, it would properly begin in Greek political science, make some modest gains in the Roman centuries, not make much progress in the Middle Ages, rise a bit in the Renaissance and Enlightenment, make some substantial gains in the $19^{\text {th }}$ century, and then take off in solid growth in the $20^{\text {th }}$ century as political science acquires genuine professional characteristics. What would be measured by this curve is the growth and qualitative improvement in knowledge concerned with the two fundamental questions of political science: the properties of political institutions and the criteria we use in evaluating them" (ALMOND, 1996, p. 50). ["Se fosse para considerarmos a história da Ciência Política em época, ela começaria propriamente com a Ciência Política grega, teria tido alguns ganhos modestos nos séculos romanos, não teria feito muitos progressos na Idade Média, teria uma certa inflexão na Renascença e no Iluminismo, teria obtido ganhos substantivos no século XIX e então decolado com crescimento sólido no século XX, em que a Ciência Política adquire características profissionais genuínas. $\mathrm{O}$ que deveria ser medido por essa curva é o crescimento e o desenvolvimento qualitativo do conhecimento relativo a duas questões fundamentais da Ciência Política: as propriedades das instituições políticas e os critérios que utilizamos para avaliá-las" (tradução dos revisores).] 
fenomenologia de Husserl e Heidegger, afirmava, em um texto clássico sobre os fundamentos da filosofia política: "Hoje, a filosofia política está em um estado de decadência, e quiçá de putrefação, é que ainda não desapareceu completamente. Não só há um desacordo completo em relação a seu objeto, método e função; sua própria existência tem sido colocada em questão. O único ponto sobre o qual os professores de Ciência Política concordam se refere à utilidade do estudo da história da filosofia política" (STRAUSS, 1959, p. $17)^{6}$.

Se for verdade que o desenvolvimento de uma Ciência Política de caráter comportamentalista colocou severos questionamentos para uma reflexão de tipo filosófica sobre a política, é necessário questionar, ou ao menos qualificar, o significado concreto desse suposta decadência da filosofia política, isto como passo necessário para se ter uma compreensão mais acabada do "ressurgimento" da filosofia política na década seguinte.

Bhikhu Parekh (1996, p. 504), analisando o significado da morte da filosofia política atribuído por Laslett, afirma que a produção teórica das décadas de 1950 e 1960 foi de uma enorme riqueza intelectual. Alguns trabalhos são demonstrações evidentes desta avaliação: as obras de Michael Oakeshott, a "Introdução" ao Leviatã de Thomas Hobbes e Rationalism in Politics (1962), nos quais o autor propõe uma nova concepção da natureza da filosofia política desafiando o racionalismo dominante do pensamento ocidental responsável, na sua visão, pelas tragédias do período, e, ao mesmo tempo, oferecendo uma versão original do conservadorismo separada de sua tradicional associação com a religião, a moral, o historicismo ou o nacionalismo. Também, durante esse período, assistimos à publicação das obras fundamentais de Hannah Arendt, que se transformariam em textos seminais na filosofia política do século XX, como The Human Condition (1958), Between Past and Future (1961) e On Revolution (1963). Nes-

\footnotetext{
6 No prefácio de seu influente livro Politics and Vision, Sheldon Wolin colocava uma apreciação similar: "Em muitos círculos intelectuais existe hoje uma marcada hostilidade em relação, ou ainda um desprezo, à filosofia política na sua forma tradicional. Minha esperança é que este volume, se não conseguir aclamar aqueles que estão ansiosos por jogar fora o que ainda existe da filosofia política tradicional, ao menos seja exitoso em deixar claro o que tem sido descartado" (WOLIN, 2004, p. XXIII).
}

sas obras, Arendt problematiza o conceito de natureza humana, criticando o caráter apolítico da filosofia política tradicional, e argumentando que seus pressupostos e conceitos precisam ser radicalmente revisados para que se entenda os fenômenos totalitários como o nazismo e o stalinismo. Isaiah Berlin, por sua vez, publica uma série de ensaios importantes entre os quais dois dos mais influentes, e que se tornariam clássicos na reflexão política, são: "Two Concepts of Liberty" (1958) e "Does Political Theory Exist?" (1962). Nessas obras Berlin busca desafiar o monismo moral de grande parte da filosofia política, enfatizando o pluralismo de valores morais, e delineando desta maneira uma forma moderna de liberalismo, distintiva e altamente influente.

Nessas décadas observamos, do mesmo modo, o trabalho criativo e influente de filósofos políticos como Leo Strauss, C. B. Macpherson, F. A. Hayek, Karl Popper e Eric Voegelin; além disso, trabalhos pioneiros sobre autores clássicos como Hobbes, Locke, Mill, Kant e outros, que não pretendiam ser comentários das obras dos autores clássicos e, sim, obras de filosofia política, reapropriando-se de maneira crítica de idéias e conceitos clássicos para pensar o mundo político do período. Outra corrente teórica de fundamental importância durante o período foi a tentativa sistemática de elaborar uma filosofia política marxista a partir das obras de autores como Althusser, Sartre, Habermas e Marcuse. O desenvolvimento de uma filosofia política marxista estimulou a crítica social e política e levou à elaboração de alguns dos trabalhos mais importantes da tradição marxista.

A teoria e filosofia política elaborada durante das décadas de 1950 e 1960 tinham uma série de características distintivas, no entanto para os propósitos da nossa discussão podemos distinguir duas características centrais e que servem para pensar o processo de reconfiguração da década seguinte ${ }^{7}$.

Em primeiro lugar, apesar de que os diferentes escritores tiveram preocupações distintas, todos eles eram conscientes de que a disciplina estava sob uma severa crítica originada em fontes diversas como o positivismo lógico, a filosofia lin-

\footnotetext{
7 Retomamos o argumento de Parekh (1996), mas
} reconfiguramo-lo para sustentar nosso argumento. 
güística, a sociologia do conhecimento, o comportamentalismo e o existencialismo. Em especial no mundo anglo-saxão, que como veremos se tornaria dominante em diferentes áreas do conhecimento, particularmente na filosofia e na filosofia política, existia uma visão amplamente aceita sobre a divisão entre elementos empíricos e normativos da explicação social, e a filosofia política tradicional definitivamente pertencia ao segundo tipo de explicação. Partia-se do pressuposto de que os valores não podiam ser defendidos de maneira objetiva, as perspectivas de caráter normativo não eram mais preferências pessoais que reivindicavam ilegitimamente validade universal. Os teóricos que estamos analisando discordavam dessa avaliação e enfatizavam que a filosofia política era uma forma de investigação necessária e relevante; ela deveria ser universal no seu alcance, crítica na sua orientação e buscar dar uma perspectiva racional da vida política. Para esses teóricos a contribuição essencial da filosofia política consistia em destacar as características fundamentais da vida humana em geral e da vida política em particular, criticar os projetos ideológicos irrealizáveis e clarificar as formas prevalecentes do discurso político. A filosofia política deveria focar suas análises na interpretação crítica dos processos sociais e políticos, e seu caráter prescritivo era derivado do processo anterior; as análises deveriam operar num nível de abstração que tornava complexa a recomendação de instituições e políticas específicas (PAREKH, 1996, p. 505).

Em segundo lugar, os teóricos que escreveram durante esse período tinham vivido os horrores da Segunda Guerra Mundial, o surgimento do nazismo e do stalinismo, e uma parte importante de suas teorizações concentrou-se nas tendências latentes na civilização ocidental que levaram a esses horrores. Eles rastrearam as raízes destas tendências no racionalismo (Oakeshott), no historicismo (Popper), no monismo moral (Berlin), no surgimento do animal laborans (Arendt), no relativismo (Strauss) e da lógica do capitalismo (Marcuse e outros pensadores marxistas). Não obstante serem oponentes ferozes do comunismo, a maioria dos filósofos políticos não-marxistas tinha uma visão crítica da democracia e da sociedade liberal. Como afirma Parekh (idem, p. 506), estes autores eram, em muitos casos, extremamente críticos dos chamados valores liberais, censurando a visão associal do individuo, a visão anistórica da racionalidade, o subjetivismo moral, a conexão inerente entre liberalismo e capitalismo, e do que consideravam uma visão instrumental da política.

Não é fácil entender as razões teóricas e práticas pelas quais as análises da época diagnosticavam a morte da filosofia política ou seu declínio terminal, apesar da fecundidade teórica dos autores do período. Sem dúvida o triunfo da Ciência Política de caráter comportamentalista, a desqualificação destas perspectivas como não "verdadeiramente" filosóficas pelo positivismo, e a crença que o engajamento filosófico com os autores do passado era "história das idéias" e não filosofia política, cumpriram um papel relevante. No entanto, de forma paradoxal, outro fator também teve importância fundamental, o surgimento de uma perspectiva normativa, cada vez mais dominante, na filosofia política. A grande maioria dos autores das décadas de 1950 e 1960 concebia a filosofia política como um questionamento reflexivo e descritivo preocupado fundamentalmente em compreender ao invés de prescrever. Considerando que os escritos desses autores não preenchiam os estritos critérios estabelecidos pelos críticos do que deveria constituir uma "verdadeira" filosofia política, estes pronunciaram de forma previsível a morte da disciplina (idem, p. 506507).

Em resumo, parece que - ainda será necessário um aprofundamento deste diagnóstico - durante as décadas de 1950 e 1960 assistimos menos a um processo de morte ou declínio da teoria e da filosofia política e, sim, a um profundo processo de "esgotamento" - aqui o termo talvez seja excessivo ou impreciso - de determinadas perspectivas analíticas que teve como conseqüências uma profunda reconfiguração, desde vários pontos de vista, da prática teórica.

\section{RETOMADA DA TEORIA POLÍTICA}

Observamos, durante as décadas de 1960 e 1970, um processo de "ressurgimento" ou de profunda reconfiguração da teoria e da filosofia política. Várias explicações procuraram, porém nenhuma completamente satisfatória, entender e explicar esse "ressurgimento". A explicação mais consensual sobre este processo é que a Teoria Política se desenvolveu porque seu principal adversário, o comportamentalismo, entrou em crise.

A Ciência Política comportamentalista tinha retomado as categorias e distinções-chave de uma 
filosofia particular, o positivismo filosófico, assim uma história adequada "revolução comportamentalista" deve incluir, também, uma consideração da ascensão e da queda de seus fundamentos filosóficos (FARR, 1995).

Como afirma Terence Ball, o positivismo filosófico teve uma função normativa particularmente importante para o comportamentalismo; o positivismo definia os parâmetros de uma elaboração verdadeiramente científica, e o que a Ciência Política deveria ser para que fosse considerada ciência. Em primeiro lugar, a Ciência Política deveria distinguir "fatos" e "valores"; em segundo lugar, ela deveria privilegiar uma abordagem "empírica" em detrimento de uma "normativa" e adotar, como conseqüência, uma abordagem de caráter explicativo. Uma explicação científica, de acordo com esses pressupostos positivistas, dependia da descoberta e desenvolvimento de leis objetivas e universais. A Teoria Política "tradicional", por sua vez, não se adequava aos critérios positivistas de significância cognitiva e suficiência explicativa; por esses motivos, ela era rejeitada, considerada não-científica ou, no máximo, como pré-científica e, portanto, destinada a ser superada. A Teoria Política deveria, continua Ball, concentrar seus esforços no estudo dos pensadores clássicos do passado e deixar que os problemas políticos contemporâneos fossem abordados pela Ciência Política, estabelecendo desta forma uma dicotomia básica entre os elementos normativos e empíricos da explicação social. Herdeira como era de uma filosofia da ciência específica, o destino da Ciência Política comportamentalista esteve ligado à crise do positivismo filosófico. No entanto, seria incorreto ou simplista relacionar o ressurgimento da $\mathrm{Te}-$ oria Política exclusivamente com a crise do positivismo filosófico e o declínio associado do comportamentalismo (BALL, 2004, p. 4).

Um segundo elemento a ser considerado refere-se às relações entre elaboração teórica e o movimento do mundo político real. Durante a década de 1960 assistimos a uma série de eventos fundamentais para a fortuna da Teoria Política. A agitação política serviu como fundamento da atividade teórica; alguns dos eventos mais importantes foram, só para nos concentrar nos Estados Unidos, o movimento pela liberdade de expressão na Universidade da Califórnia em Berkeley, o movimento pelos direitos civis e os protestos contra a Guerra do Vietnã e pela retirada das tropas estadunidenses de lá. Esses acontecimentos centrais da referida década colocaram uma série de assuntos que eram problemas políticos antes de serem questões teóricas: a legitimidade do Estado, os limites da obrigação política, a natureza da justiça e as preocupações com a consciência política da população.

Foi nesse contexto teórico e político que surgiram novas obras teóricas fundamentais na tradição da Teoria Política e da história do pensamento político. Foram nesses anos que John Rawls desenvolveu as idéias centrais que cobrariam forma sistemática em Uma teoria da Justiça (1971), uma obra voltada ao exame de temas que ganharam proeminência nos agitados anos sessenta: políticas redistributivas, objeção de consciência, e legitimidade do poder do Estado. Também, nesse período, surgem com força no mundo anglosaxão as contribuições de Quentin Skinner e da Escola Contextualista do pensamento político (também conhecida como "Escola de Cambridge").

O desenvolvimento dessas duas correntes teóricas parece sintetizar o processo de "ressurgimento", e reconfiguração, da Teoria Política a partir da década de 1970. É possível, ainda que de forma hipotética, tentar analisar algumas das características dominantes destas novas formas de teorização.

Um primeiro elemento refere-se ao deslocamento geográfico da produção intelectual. Começa a existir, a partir da década de 1970, uma crescente hegemonia intelectual do mundo anglosaxão, e especialmente da produção norte-americana, no âmbito das ciências sociais. A ascendência da filosofia analítica e da economia neoclássica, ambas as disciplinas com certa tradição no mundo anglo-saxão, são exemplos deste processo de deslocamento ${ }^{8}$. O ressurgimento da Teoria Política no período que estamos analisando esteve acompanhado deste novo predomínio da produção anglo-saxão, e em especial de autores norteamericanos, e teve como conseqüência também uma mudança importante na própria abordagem da disciplina.

Em segundo lugar, podemos ver uma reconfiguração da Teoria Política do próprio pon-

${ }^{8}$ Sobre esse deslocamento geográfico, ver Anderson (1990). 
to de vista político. Como analisamos anteriormente, a maioria dos teóricos das décadas anteriores era de pensadores conservadores ou críticos profundos da democracia e dos valores liberais. Ainda que o liberalismo fosse hegemônico do ponto de vista dos valores políticos e sociais, não o era do ponto de vista da Teoria Política. Foi só a partir da década de 1970 que a Teoria Política se transformou em hegemonicamente liberal; apesar da existência de outras correntes de pensamento nãoliberal, como os comunitaristas, somente para citar um exemplo.

Por último, assistimos a uma mudança profunda do ponto de vista epistemológico, caracterizada pela crise do positivismo filosófico e pelo surgimento da filosofia analítica. Uma análise detalhada da filosofia analítica está fora das possibilidades do presente trabalho, no entanto é possível considerar algumas das críticas, temas e conceitos que influenciaram de forma marcante as duas correntes da Teoria Política que estamos analisando.

Um dos elementos centrais se refere à relação da filosofia analítica com a lingüística; a crítica da utilização do formalismo lógico permitiu a volta da linguagem ordinária ao centro das análises (ordinary language). A crítica do formalismo permitiu recuperar os aspectos semânticos e pragmáticos da linguagem, por oposição ao aspecto sintático, e para isso foram centrais as obras de Wittgenstein, de J. L. Austin (particularmente How To Do Things with Words, de 1962) e também de J. R. Searle (Speech Acts, de 1969). Esses textos também serviram como ponto de partida para que autores como Skinner pudessem recolocar a identidade histórica da Teoria Política.

Outro elemento de fundamental importância se refere ao tema das proposições éticas. $\mathrm{O}$ positivismo lógico em sua crítica à metafísica, $\mathrm{e}$ que englobava também a moral, afirmava que as proposições éticas não eram verificáveis empiricamente, e alguns positivistas, inclusive Ayer, sustentam sua crítica às proposições metafísicas a partir de questões lógicas afirmando que elas não estão "bem-formuladas". No entanto, a pergunta que o positivismo lógico não conseguia responder era que: Se os enunciados de natureza moral simplesmente não tinham sentido, por que desempenhavam um papel tão importante no pensamento e na vida dos homens (cf. BELAVAL, 1981)?
Uma das teses centrais da filosofia analítica em sua crítica ao positivismo lógico é a inadequação da formalização tradicional para o estudo dos enunciados éticos; a concepção global que grande parte dos lógicos tem da linguagem natural é, segundo esta interpretação, falsa ou pelo menos parcial, o que levaria a uma perspectiva reducionista. Para a filosofia analítica o uso descritivo da linguagem não era o único uso, nem o mais importante.

As pesquisas de Wittgenstein e de Austin levaram a questionar a noção segundo a qual a única e principal função das palavras é "descrever" alguma coisa, e expuseram a idéia central de que na maioria das vezes "atuamos ao falar". A filosofia analítica não pretendia negar a função teórica e descritiva da linguagem natural, nem reduzir a uma função exclusivamente pragmática, seu objetivo era restabelecer o equilíbrio entre as diversas formas de comunicação lingüística e em particular reconhecer aquelas descuidadas pelos filósofos (idem).

A crítica levada adiante pela filosofia analítica cumpriu um papel-chave no processo de reconfiguração da Teoria Política a partir da década de 1970. Por uma parte, dando à linguagem e à filosofia da linguagem um lugar central na sua elaboração teórica, e colocando uma série de conceitos que seriam reapropriados pelos historiadores do pensamento político para redefinir os termos nos quais as pesquisas eram realizadas. Por outra, a crítica da filosofia analítica permitiu avançar da análise redutora para a análise neutra, possibilitando que a ética, e os juízos morais, não fossem tratados como um discurso inferior ao discurso teórico, e afirmado a tese de que o discurso prático, isto é, o discurso ético, era distinto do discurso teórico.

Desta forma, a crítica do positivismo lógico realizada pela filosofia analítica preparou o caminho para o ressurgimento da Teoria Política e da história do pensamento político, no entanto com características bastante diferentes das teorias desenvolvidas nas décadas anteriores; assim o ressurgimento implicou de fato uma profunda reconfiguração do método e do objeto da prática teórica.

O objetivo daqui em diante é realizar uma reconstrução dos principais desenvolvimentos teóricos das últimas décadas partindo-se desse pressuposto de um processo de profunda reconfiguração. 


\section{A OBRA DE RAWLS}

A publicação de Uma teoria da Justiça foi recebida como o tratado de filosofia política mais importante do século XX, e considerada uma retomada da discussão política distanciando-se da indiferença apolítica da filosofia analítica desenvolvida até então ${ }^{9}$. A filosofia política, a partir de uma perspectiva analítica, demonstrava que podia enfrentar os problemas sociais do momento, defender direitos iguais e oferecer uma série de princípios orientadores para a distribuição dos recursos econômicos. Rawls procurava desenvolver uma concepção especificamente liberal da política, como surgia do título de sua segunda obra fundamental Liberalismo político (1993). Para Wolin (2004), a motivação do projeto estava implícita em certa justaposição da terminologia, Rawls estava propondo uma solução liberal para o que ele considerava como a evidente crise da democracia constitucional moderna ${ }^{10}$.

A primeira obra de Rawls foi uma tentativa de prover uma justificativa filosófica para o Welfare State liberal-democrático do pós-guerra. De fato, como afirma Kymlicka (2002), esta ligação com o Welfare State ajuda a explicar a ampla influência das teorias políticas do liberalismo igualitário. Os anos 1950 e 1960 presenciaram a enorme expansão do Estado na maioria das democracias ocidentais, no entanto não existia nenhuma elaboração teórica, do ponto de vista filosófico, que servisse de justificativa para esse processo. $\mathrm{O}$ apare-

9 "Rawls's book had an immense impact and enabled moral and political philosophy to stop seeing themselves as purely (or at least primarily) descriptive approaches: they could now claim an active role in the discussion and resolution of public problems” (NEHAMAS, 1997, p. 217). ["O livro de Rawls teve um impacto imenso e permitiu que a Filosofia Moral e Política parasse de ver-se como abordagens puramente (ou, pelo menos, primariamente) descritivas: ela poderia agora reivindicar um papel ativo na discussão e na resolução dos problemas públicos" (T. R.).] Para uma análise do impacto da obra na filosofia política contemporânea, ver também Klymlicka (2002).

10 Retoma-se nos pontos fundamentais a interpretação de Sheldon Wolin sobre Rawls. O objetivo não é fazer uma análise exaustiva da obra de Rawls, o que ficaria fora das possibilidades do presente texto, e, sim, oferecer alguns elementos que permitam entender os desenvolvimentos da Teoria Política das últimas décadas. Para uma interpretação diametralmente diferente da obra de Rawls ver, dentro da literatura brasileira, cf. Vita (2000). cimento da obra de Rawls, e de outras obras de liberais igualitários, nos anos 1970, parecia prover com argumentos satisfatórios, do ponto de vista intelectual, para defender no debate político esse processo de expansão.

A visão de Rawls representou algumas mudanças importantes no discurso sobre a justiça, que ilustravam como a tradição filosófica tinha estabelecido laços com a economia e com a teoria jurídica; construindo desta forma um novo tipo de filosofia política, com algumas características particulares: seu alto nível de abstração, sua complexidade técnica e sua moderação do ponto de visto político.

Uma teoria da Justiça adotava os principais elementos da problemática liberal, as tensões entre liberdade e igualdade, a distinção entre as dimensões políticas e econômicas da vida social e uma base consensual da sociedade como pressuposto político fundamental.

Colocando a justiça como a primeira virtude de todas as instituições sociais, Rawls aponta sua intenção de abordar a questão da desigualdade. A concepção de justiça é formulada primordialmente em termos econômicos como "a forma na qual as principais instituições sociais distribuem direitos e deveres e determinam a divisão das vantagens da cooperação social" (RAWLS, 1971, p. 7). A teoria da justiça era concebida como parte, talvez a mais significativa, da teoria da escolha racional. $\mathrm{O}$ ponto de partida não será o cidadão virtuoso e sim o indivíduo racional da teoria econômica; de forma congruente, o princípio definidor da cidadania é a reciprocidade, o que leva a uma importante mudança na idéia tradicional de contrato social, de uma solução política contra o poder arbitrário passa a privilegiar uma concepção de negociação.

A centralidade atribuída à economia, como afirma Wolin, tem importantes conseqüências políticas para Rawls. O papel da administração é ampliado, enquanto a governança é concebida tecnocraticamente, reduzida a um Estado autônomo altamente centralizado independente dos poderes econômicos e sociais que supostamente deve regular. Para Rawls os arranjos de livre mercado devem ter lugar dentro de um marco de instituições jurídicas que regulem as tendências gerais dos sucessos econômicos e conservem as condições sociais necessária para a justa igualdade de oportunidades. Rawls concebe a autonomia regu- 
ladora do Estado, e seu poder para transformar as desigualdades sócio-econômicas, sem examinar a estrutura econômica da sociedade que concentra tanto riqueza como poder. Seu silêncio sobre as estruturas do poder econômico não é uma omissão, mas um gesto de legitimação (WOLIN, 2004, p. 531).

A justiça rawlsiana baseia-se em dos princípios básicos. O primeiro princípio exige direitos e obrigações iguais para todos. O segundo estipula que as desigualdades podem ser consideradas como justas se, e somente se, elas "produzem benefícios compensatórios para todos" e "em particular para os menos avantajados da sociedade" (RAWLS, 1971, p. 14-15). A desigualdade é identificada fundamentalmente como distribuição desigual de recursos básicos e oportunidades de forma tal que impedem ou debilitam o exercício dos direitos.

Sob o segundo princípio, a desigualdade é considerada sistêmica, no entanto potencialmente benéfica para os menos avantajados e como conseqüência não existe necessidade de uma reforma radical. A desigualdade é inerente, mas pode ser mitigada. Em outros momentos de sua obra Rawls sugere que as causas da desigualdade são externas ao sistema, aqui a desigualdade é caracterizada como um resultado desafortunado das condições sociais imprevisíveis ou talentos naturais individuais que são impossíveis de controlar totalmente ou de eliminar. No entanto, o argumento evita atribuir a origem das desigualdades à estrutura de classes, preconceitos históricos de raça ou gênero, políticas públicas desiguais, ou mudanças tecnológicas que produzem populações supérfluas. Apesar de a justiça rawlsiana focar-se no melhoramento da sorte dos menos avantajados, não existe nenhuma promessa de que a justiça implique em erradicar a desigualdade.

A desigualdade é, desta forma, atribuída à ordem do irracional ou do contingente, ou à loteria. Os benefícios compensatórios da desigualdade não parecem desafiar as desigualdades estruturais do sistema de poder. Ao mesmo tempo, Rawls é cético sobre o valor da participação como meio de contrarrestar a influência das corporações econômicas. Os direitos econômicos, como a participação dos trabalhadores nas decisões das empresas, são excluídos explicitamente e desta forma se evita a questão crucial das conseqüências políticas da organização econômica. Ao não reco- nhecer o sistema econômico como um sistema de poder ou conjeturar sobre qualquer meio de resistência popular a ele, a visão rawlsiana da justiça evita qualquer desafio direto ao sistema capitalista e a sua política concentradora (WOLIN, 2004 , p. 532-533).

Desde o momento de sua publicação Uma teoria da Justiça recebeu numerosas críticas, às que Rawls tentou responder em uma diversidade de escritos; nestes trabalhos Rawls começou a desenvolver uma reformulação radical de sua concepção de justiça, recortando suas pretensões "universalistas" e rasgos "metafísicos" para convertê-la em uma doutrina "meramente" políti$\mathrm{ca}^{11}$. A publicação de sua segunda obra central, Liberalismo político, em 1993, representou o ponto mais importante deste processo de reformulação, um dos problemas centrais era que sua teoria não representaria uma concepção realmente neutral frente às distintas concepções de bem sendo, portanto, uma teoria incapaz de assegurar as bases da própria estabilidade. $\mathrm{O}$ desafio era elaborar uma concepção de justiça, e abordar a difícil questão da política, de um ponto de vista estritamente liberal.

Para Wolin, Liberalismo político é menos uma continuação das preocupações centrais de Uma teoria da Justiça e mais uma obra que implica algumas mudanças fundamentais do ponto de vista teórico. O discurso centrado em temas econômicos, administrativos e de políticas públicas, junto com o problema da desigualdade, praticamente desaparece e é substituído pela ênfase na ortodoxia política, a importância da cultura política e no papel do cidadão (WOLIN, 2004, p. 539). A mudança mais significativa é que o conflito de doutrinas passou a ser a preocupação central no lugar das desigualdades sócio-econômicas. Esse tema representado pelas doutrinas abrangentes, afirma Rawls, coloca um perigo para a própria existência da sociedade democrática. As doutrinas compreensivas são definidas como um sistema de crenças que "abrange todos os tipos de assuntos, desde a conduta individual, as relações pessoais até a organização da sociedade como um todo e o direito da gente" (RAWLS, 1993, p. 13).

11 Em particular, "Justice as Fairness: Political not Metaphysical" (1985) e "The Domain of the Political and Overlapping Consensus" (1989). 
A principal tentativa de Liberalismo político é mostrar que é possível construir, num contexto de existência de um "pluralismo razoável” de concepções de bem, uma concepção de justiça compartilhada e que funcione; para isso Rawls busca evitar os desacordos entre a multiplicidade de doutrinas existentes e identificar as bases possíveis de um acordo suficientemente amplo e profundo. Com esta finalidade, Rawls apresenta sua teoria como uma concepção "política" da justiça. O fato de defender uma concepção "política" de justiça não significa que ela seja complemente distinta de uma concepção moral; como afirma Rawls, a concepção política de justiça é uma concepção moral (idem, p. 11), porém elaborada em relação com um objeto específico da estrutura básica da sociedade.

Rawls apela à idéia de um consenso sobreposto (overlapping consensus) destinado a tornar possível que concepções compreensivas razoáveis e opostas confluam em certos acordos básicos. Segundo Rawls, o overlapping consensus faz referência a um acordo entre pessoas razoáveis, que só aceitam doutrinas compreensivas razoáveis (idem, p. 139). Nesse sentido, o consenso sobreposto aparece como a única forma de permitir que, em um contexto pluralista, cada indivíduo chegue a concordar com uma concepção pública de justiça; esse consenso só será possível uma vez que a concepção pública em questão apareça como razoável aos olhos de todos. Assim, o overlapping consensus é uma expressão do que se denomina "razão pública compartilhada" pelo conjunto da sociedade. A idéia de razão pública resulta especialmente importante na explicação de como é possível defender uma constituição justa e estável dentro de uma sociedade pluralista.

De alguma forma, o ideal de razão pública vem a desenvolver o critério liberal de acordo com o qual um governo democrático não deveria justificar suas políticas apelando a valores religiosos (GARGARELLA, 1999).

O liberalismo político, proposto por Rawls, aceita a democracia como um princípio formal de cidadãos livres e iguais, e ao mesmo tempo condena explicitamente outras tradições políticas como o humanismo cívico, uma forma de também desaprovar uma concepção de democracia entendida como participação política. O humanismo cívico e a democracia participativa são denunciados como doutrinas compreensivas nas quais o homem é um animal social, e mesmo político, cuja essência natural é plenamente alcançada em uma sociedade democrática na qual existe uma generalizada e vigorosa participação na vida política (RAWLS, 1988). A participação, Rawls observa criticamente, é proclamada não meramente como um direito, mas como o locus privilegiado da boa vida. Uma concepção de democracia mais ampla, menos formal e mais substantiva implicaria, na visão de Rawls, entrar no âmbito das doutrinas compreensivas. Mas, de fato, o liberalismo político rawlsiano não seria também uma forma de doutrina compreensiva (WOLIN, 2004, p. 549).

Como afirma Wolin, é possível ver como a mudança de ênfase das obras reflete problemas e preocupações diferentes enfrentados por Rawls. É possível considerar que a primeira das obras expressa um contexto histórico e político específico, uma conjuntura que surge com a instauração do New Deal - enquanto Estado regulador e de bem-estar social -, com sua confiança na resolução dos problemas sociais mediante uma combinação de administração e políticas específicas, até a proposta de Great Society de Lyndon Johnson, cujos principais objetivos de reforma social eram a eliminação da pobreza e o fim da discriminação racial. Dessa forma, Uma teoria da Justiça, com sua ênfase econômica na distribuição de recursos e política no valor fundamental dos direitos, refletia a tradição do Welfare State e a luta pelos direitos civis das décadas anteriores. Em contraposição, sua obra posterior, Liberalismo político, representa o liberalismo em uma era de crescente predomínio conservador, e de "guerras culturais", um liberalismo que se inclina para o centro e que como conseqüência deixa de lado o problema de tentar resolver a relação entre desigualdades econômicas e sociais e igualdade política. Esta última obra de Rawls desloca o problema da democracia do âmbito material, para recolocá-lo no âmbito cultural ou ideológico (WOLIN, 2004, p. 530).

\section{V.AESCOLADE CAMBRIDGE}

Durante a década de 1960 foram publicados uma série de trabalhos de caráter metodológico que colocaram as fundações do trabalho dos historiadores das idéias. Três desses trabalhos foram de particular relevância: John Pocock publicou o ensaio "The History of Political Thought: A Methodological Enquiry” (1962); John Dunn, "The Identity of the History of Ideas" (1968); em 1969 
aparecia "Meaning and Understanding in the History of Ideas", de Quentin Skinner, o mais influente dos textos metodológicos desSa nova historiografia ${ }^{12}$.

O objetivo central desses trabalhos era questionar a abordagem tradicional da Teoria Política e sustentar a identidade histórica da Teoria Politica; o método apropriado para desenvolver seu estudo era o método histórico, e o significado dos conceitos e idéias-chave dos textos centrais da Teoria Política deveria ser entendido partindo-se da noção de um significado historicamente construído (HAMPSHER-MONK, 2001, p. 159-60).

As origens desse processo de reformulação devem ser buscadas na análise lingüística, um dos desdobramentos da filosofia analítica, como temse analisado, adotada por alguns teóricos da Universidade de Cambridge na década anterior -1950 -, e nas teorias dos atos de fala (speech-acts) desenvolvidas em Oxford. O foco principal destas visões se concentrava na ampla variedade de coisas que podiam ser reconhecidas como ditas, e especialmente na diversidade de contextos lingüísticos que iriam determinar o que poderia ser enunciado e que, ao mesmo tempo, podiam ser modificados por essas enunciações. Os historiadores do pensamento político apropriaram-se dessas concepções e desenvolveram uma análise crítica com relação aos fundamentos epistemológicos de suas pesquisas. Como afirma Pocock, era curioso que a série Philosophy, Politics and Society, publicada por Peter Laslett a partir de 1956, se dedicasse quase inteiramente ao exame e investigação de problemas políticos, e escassamente à definição de seu status histórico ou à historiografia do debate político; talvez uma demonstração das dificuldades de estabelecer um diálogo construtivo entre filosofia e história. Uma exceção fundamental dessa tendência, de significativa importância, foram os textos de Pocock, Dunn e Skinner também publicados nessa série.

De forma paradoxal, ao mesmo tempo em que Laslett anunciava que "a filosofia política estava morta", a história do pensamento político começava um processo de profunda reformulação, em grande medida como conseqüência do próprio trabalho de Laslett - em particular graças a seu tra-

12 Sobre essa nova historiografia do pensamento político ver, entre outros, Silva (2009a; 2009b). balho editorial sobre os textos de Robert Filmer e John Locke (cf. LASLETT, 1949; 1960). Esses trabalhos colocaram os fundamentos históricos e teóricos que deveriam guiar as pesquisa dos historiadores do pensamento político. A partir desses elementos começava a tomar forma uma historiografia com ênfases características. Em primeiro lugar, sobre a variedade das linguagens em que o debate político podia ocorrer; em segundo lugar, sobre os participantes do debate político, vistos como atores históricos, reagindo uns em relação aos outros em uma diversidade de contextos históricos, e particularmente lingüísticos, conferindo uma textura extremamente rica à história, que podia ser resgatada (POCOCK, 2003a, p. 24-25).

Como afirma Pocock (idem), as formulações teóricas de Thomas Kuhn e o fim do predomínio de popperismo, tiveram ampla importância nesse processo de reformulação, no entanto foi na metade da década de 1960 , com a publicação dos textos metodológicos de Skinner ${ }^{13}$, que os historiadores do pensamento político começaram a mostrar a lógica de sua própria pesquisa e a aprofundá-la nas áreas em que ela se aproximava da filosofia da linguagem.

Quentin Skinner tomou como ponto de partida de sua elaboração teórica a aplicação de uma posição filosófica particular, a análise dos atos de fala (speech acts) de Austin. O trabalho inicial de Pocock, por sua vez, baseava-se numa tradição de prática intelectual que explorava uma variedade de fundamentos metodológicos, porém articulados de forma crescente e original no conceito de linguagem. Podemos ver, portanto, posições contrastantes, Skinner partiu de uma posição metodológica desafiante, específica e combativa (SKINNER, 2002b), e em contraste Pocock tentou um tipo de explicação mais branda, reconhecendo o caráter exploratório do estudo da história do pensamento político. Pocock parte de uma aproximação de tradição, inspirada em Michael Oakeshott, que permite entender tanto o objeto de análises como as recomendações de como abordálo. Teorizar em diálogo com uma tradição implica necessariamente um processo de abstração dela. $\mathrm{O}$ equívoco na história do pensamento político

13 De particular importância é "Meaning and Understanding in the History of Ideas", de 1967 mas publicado em 1969. 
consiste na tentativa equivocada de apresentar a história de uma tradição discursiva não estabelecendo evidências históricas para suas continuidades conceituais, mas sim por meio da identificação especulativa das conexões ou, ainda pior, construindo exemplos canônicos mediante a abstração filosófica (POCOCK, 2003a, p. 160-161) ${ }^{14}$.

O trabalho de Skinner tem combinado desde o começo com um trabalho substantivo sobre o pensamento político moderno (SKINNER, 2009), tendo uma preocupação metodológica marcante. Sua posição tem acentuado uma característica fundamentalmente lingüística do trabalho do historiador do pensamento político.

Alguns conceitos centrais dos trabalhos de Ludwig Wittgenstein - Philosophical Investigations - e de J. L. Austin - How to Do Things with Words - são retomados na análise de Skinner. Em relação a Wittgenstein, retoma a idéia de que os significados das palavras não podem ser pensados isoladamente, seu significado deve ser compreendido dentro de jogos de linguagem específicos e, de forma mais geral, dentro de formas de vida particulares; de Austin retoma a idéia de que para analisar o significado das palavras é fundamental entender que elas também são fatos, e que é possível fazer coisas com as palavras ${ }^{15}$.

Ambos os autores, segundo a leitura de Skinner, sustentam que para compreender qualquer enunciado sério é necessário captar alguma coisa que vai além e está por cima do sentido e da referência dos termos utilizados para expressá-lo. Seria necessário, na formulação particular de Austin, encontrar os meios para recuperar aquilo que o agente poderia ter feito ao dizer aquilo que ele diz e, portanto, entender o que o agente teria desejado significar ao utilizar uma expressão com esse exato sentido e referência. Dessa forma as intuições de Wittgenstein e Austin oferecem uma hermenêutica excepcionalmente valiosa para os historiadores intelectuais (SKINNER, 2002b, p. 103-104).

No momento da fala e da escrita o autor também está realizando uma performance discursiva e isso é particularmente válido no caso da ação política. Aliada a essa noção de performance está

\footnotetext{
14 Essa crítica também está presente em Skinner (2002a).

15 Outra influência importante no trabalho de Skinner foi a filosofia da história de R. G. Collingwood.
}

a difícil noção de intenção. Skinner formula seu apelo à historicidade de uma interpretação em termos de recuperação da intenção do autor. Como conseqüência, um dos elementos centrais de uma abordagem histórica do pensamento político será enfatizar a importância de resgatar as intenções que um autor teria ao elaborar seu texto. A ênfase nas intenções do autor leva Skinner a analisar o contexto no qual aquele escreve; as intenções do autor não podem existir de forma independente da linguagem em que o texto é construído.

Como afirma Skinner (idem), o contexto apropriado para entender as expressões de determinado autor será sempre qualquer contexto que permita apreciar a natureza da intervenção constituída por suas expressões; para recuperar esse contexto em qualquer caso particular será necessário realizar uma pesquisa histórica extremamente ampla, tanto no seu espectro como em seus detalhes. Se o historiador for capaz de identificar esse contexto com suficiente precisão, será possível interpretar o que o escritor estava fazendo ao dizer o que ele diz.

O autor, nessa visão, habita um mundo historicamente determinado, que é apreensível somente por meios disponíveis graças a uma série de linguagens historicamente constituídas. Os modos de discurso disponíveis dão-lhe as intenções que ele pode ter ao proporcionar-lhe os únicos meios de que ele poderá dispor para efetuá-las. Neste ponto, a análise busca entender a relação existente entre contexto lingüístico e os atos de fala. O método analítico proposto por Skinner aponta na direção tanto do resgate da linguagem do autor quanto das intenções, bem como de tratálo como um habitante de um universo lingüístico. Para Skinner isso não implica reduzir o autor a um mero porta-voz de sua própria linguagem. Quanto mais complexo, e até quanto mais contraditório o contexto lingüístico em que ele se situa, mais ricos e ambivalentes serão os atos de fala que ele terá condições de emitir e maior será a probabilidade de que esses atos atuem sobre o próprio contexto lingüístico e induzam modificações no interior dele. Nesse momento, a história do pensamento político torna-se uma história da fala e do discurso, das interações entre a fala do autor e o contexto lingüístico no qual habita. Sustenta-se não somente que essa história do pensamento político é uma história do discurso, mas que ela tem uma história justamente em virtude de tornar-se discurso (POCOCK, 2003a, p. 27-28). 
Por sua vez, na interpretação de Pocock seguindo Oakeshott - a Teoria Política pode ser abordada por diferentes enfoques, pode ser pensada como modos de experiência, históricos ou práticos, ou a partir de disciplinas rivais; uma análise deste tipo parece destacar a tensão fundamental entre o histórico e o filosófico. A análise de Pocock tem combinado dimensões lingüísticas e sociológicas; na visão do autor cada sociedade desenvolve um determinado vocabulário político estável compreendendo uma série de conceitos agrupados em um domínio interno formado pela gramática e sintaxe e com repertório de associações. A existência de vários grupos suficientemente segregados dentro de uma sociedade pode levar ao desenvolvimento de dois ou mais vocabulários (HAMPSHER-MONK, 2001, p. 161).

Como conseqüência, afirma Pocock, uma das tarefas centrais do historiador do discurso político é estabelecer a linguagem ou linguagens em que determinada passagem do discurso político estava sendo desenvolvida. Essas "linguagens" serão na realidade sub-linguagens, idiomas e retóricas mais do que linguagens no sentido estrito; essas linguagens também variam no seu grau de autonomia e estabilidade. A tarefa do historiador é buscar os modos de discurso estáveis o suficiente para permitir seu uso por parte de mais de um locutor e para apresentar o caráter de um jogo definido por uma estrutura de regras para mais de um jogador. Isso possibilitará considerar o modo pelo qual os jogadores exploram as regras uns contra outros, e ao mesmo tempo, como atuam sobre as regras com a conseqüência de alterá-las. Essas linguagens variam também na origem e, por conseguinte, em conteúdo e caráter. Algumas podem ter sua genealogia nas práticas institucionais de determinada sociedade: como os jargões profissionais de filósofos, teólogos, juristas, comerciantes, ou aqueles que se tornaram reconhecidos como integrantes da prática política ou como formuladores do discurso político. Para o autor pode-se aprender muito sobre a cultura política de uma determinada sociedade nos diversos momentos de sua história, observando-se que linguagens assim originadas foram sancionadas como legítimas integrantes do universo do discurso público (POCOCK, 2003a, p. 31; ver também POCOCK, 1962).

Grande parte da prática do historiador do pensamento político, continua Pocock, consiste em aprender a ler os diversos idiomas do discurso político na forma em que se encontravam disponíveis na cultura e na época que o historiador está estudando: identificá-los à medida que aparecem na textura lingüística de uma determinada obra e saber o que eles comumente teriam tornado possível ao autor do texto "dizer" aquilo. Em certo grau o processo de aprendizado é um processo de familiarização, mas o intérprete não pode permanecer meramente passivo e receptivo à linguagem que lê, com freqüência será necessário empregar certos procedimentos de detecção que tornem possível construir e validar hipóteses, no sentido de estabelecer que tais e tais linguagens estavam sendo empregadas e podiam ser empregadas de tais e tais maneiras. Nessa linha de trabalho, o historiador das idéias terá inevitavelmente de se confrontar com problemas de interpretação, de tendência ideológica e com o círculo hermenêutico (POCOCK, 2003a, p. 33).

Em um de seus primeiros trabalhos importantes - The Ancient Constitution and the Feudal Law (POCOCK, 2004) - Pocock identificou a existência de conflito entre duas linguagens fundamentais na Inglaterra do período: a linguagem da common law, de acordo com a qual a busca do precedente como forma de argumentar politicamente implicava a existência de um passado inalterável; e a linguagem baseada na feudal law, a partir da qual era discernível uma estrutura diferente do passado inglês. Para ambas as linguagens o passado exercia uma autoridade sobre o pressente e, portanto, os autores que utilizavam essas linguagens procuravam conhecer a verdade sobre o passado como forma de estabelecer ou contestar a legitimidade do presente.

Pocock entende que a primeira tarefa de caráter interpretativo do historiador do pensamento político deve ser identificar e construir essas linguagens e suas transformações no tempo. Explicar a produção de um autor determinado implica identificar sua relação com a linguagem ou linguagens que o autor utiliza na sua argumentação. Este segundo elemento de apresentação da linguagem sempre coloca o perigo de que a exegese se apresente como coerente quando não o é. Chamando a atenção sobre a dificuldade de resistir à tentação de se comprometer com a (como oposto a escrever história da) Teoria Política, Pocock explica a lamentável, contudo constante tendência dos historiadores da Teoria Política de tornarse filósofos (HAMPSHER-MONK, 2001, p. 161). 
Essa corrente da história do pensamento político, representada por Skinner e Pocock, tem levado a uma renovação extraordinária na história das idéias e tem tornado possível o diálogo entre historiadores e filósofos, no entanto os elementos de caráter inovador colocados por estes autores parecem chocar-se com os próprios limites internos.

Algumas críticas têm sublinhado que esta nova metodologia - a insistência do significado contextual das afirmações teórico-políticas - é politicamente impotente já que a abordagem é tão irreparavelmente histórica que seus conceitos são inadequados para os debates da Teoria Política contemporânea (idem).

Esta conseqüência distintiva da abordagem metodológica proposta não tem passado de forma inadvertida pelos próprios autores. Skinner e Dunn de maneira mais explícita, no caso de John Pocock de modo mais implícito, têm alertado para a inconveniência de utilizar argumentos e conceitos construídos sobre locuções históricas para os propósitos de uma discussão política contemporânea.

Entre as proposições polêmicas colocadas por Skinner, uma das centrais se refere à inexistência de idéias políticas duradoras que possam ser objeto de uma análise histórica apropriada. E ainda se pudessem existir, em um nível adequado de abstração, questões duradoras em Teoria Política, o tipo de respostas colocadas teriam uma especificidade historicamente determinada, desta forma não seriam relevantes para nossas preocupações presentes, e de forma mais geral, não se deveria esperar aprender nada diretamente aplicável ou relevante para nossa situação de um estudo propriamente histórico da Teoria Política (SKINNER, 2002). De fato, considerando a estrutura teórica do argumento de Skinner é possível afirmar que a desqualificação de qualquer elemento diacrônico dos conceitos políticos ou das teorias não só corresponde com as intenções do conjunto complexo de atos de fala na sua ofensiva metodológica, mas eles são também uma conseqüência estrita e lógica deles (HAMPSHERMONK, 2001, p. 167).

No entanto, isso não equivale a negar que existam lições que possam ser aprendidas da história. Para Skinner o trabalho do historiador do pensamento político deve contribuir para o entendimento do mundo social presente. Na sua aula inaugural proferida na Universidade de Cambridge como Regius Professor de História Moderna, analisando a ascensão e a queda do que denominou como uma compreensão neo-romana da liberdade civil, Skinner afirma que tornar-se consciente de nosso passado político é parte da compreensão do nosso presente. Recuperar a forma a qual os conceitos e argumentos ainda em uso foram definidos no passado é uma maneira de "evitar cair sob o feitiço de nossa própria herança intelectual. Quando analisamos e refletimos sobre nossos conceitos normativos, é fácil nos deixarmos enfeitiçar pela crença de que as maneiras de pensar sobre eles que nos foram transmitidas pela corrente principal de nossas tradições devem ser as maneiras de pensar sobre eles" (SKINNER, 1999, p. 93; cf. também SKINNER, 2002c, p. 6).

Sem dúvidas as aspirações intelectuais colocadas por Skinner são centrais para o desenvolvimento de uma Teoria Política vigorosa, e devem ser recuperadas em qualquer projeto futuro. É necessário reconhecer os avanços intelectuais colocados por esta nova abordagem do pensamento político, porém tendo cautela sobre seu caráter potencialmente despolitizador; esses desenvolvimentos, por enquanto, não se têm reconciliado com os fundamentos filosóficos sobre os quais a versão mais rigorosa desta nova história do pensamento tem se construído, e não parece existir nenhuma revisão metodológica em andamento, ao menos com um grau comparável de sofisticação técnica daquela que estabeleceu a posição original (HAMPSER-MONK, 1984) ${ }^{16}$.

\section{CONSIDERAÇÕES FINAIS}

O desenvolvimento dessas duas correntes teóricas - a Teoria Política normativa e a História do Pensamento Político - parece sintetizar o processo de "ressurgimento", e reconfiguração, da Teoria Política a partir da década de 1970.

A crítica realizada pela filosofia analítica cumpriu um papel-chave nesse processo de reconfiguração. Por uma parte, dando à linguagem e à filosofia da linguagem um lugar essencial na sua elaboração teórica, e por outra, afirmando a centralidade da discussão normativa. No entanto este ressurgimento implicou de fato numa pro-

16 Ver também sobre essa crítica Miller (1990) e Castiglione (1993). 
funda reconfiguração do método e do objeto da elaboração teórica com importantes conseqüências práticas.

Nas últimas décadas a Teoria Política continuou a se desenvolver, e ainda parece continuar com uma importante força inovadora, mas a mudança na fortuna da Teoria Política também parece acarretar problemas centrais para seu futuro desenvolvimento, ainda que um balanço dos problemas presentes seja sempre uma empresa muito provisória.

Um dos problemas centrais que aparece no horizonte é um processo de gradual despolitização da Teoria Política. Esse processo de despolitização da Teoria Política se caracteriza por uma progressiva separação entre elementos históricos e normativos da explicação social; por um lado, levando a uma naturalização dos processos sociais presentes, como verificado nas correntes normativas da Teoria Política; e por outro, a ênfase em uma abordagem histórica do pensamento político tem deixado de lado as questões teóricas e políticas relevantes do ponto de vista contemporâneo.

Como afirma Terence Ball, o recém-encontrado orgulho da Teoria Política pode ser o presságio de sua queda; para o autor a Teoria Política estaria seguindo uma trajetória bastante parecida com a que a Ciência Política comportamentalista percorreu de meados da década de 1950 até fim dos anos 1960. Para o autor, várias são as manifestações de que a Teoria Política pode encontrar um destino semelhante. Uma manifestação fundamental desse processo seria o crescente isolamento da Teoria Política com relação ao seu tema natural, a saber, a própria política. Como conseqüência, a Teoria Política estaria desenvolvendo algumas características singulares: em primeiro lugar, uma crescente especialização e profissionalização da prática teórica; em segundo lugar, um aumento da preocupação dos teóricos políticos com questões de método e uma propensão a engajar-se em disputas metodológicas e/ou metateóricas. Em suma, a Teoria Política estaria tornando-se o tipo de criatura que outrora criticava (BALL, 2004, p. 6).

Para Ball, a Teoria Política sempre encontrou um campo fecundo de elaboração teórica quanto esteve estreitamente ligada à política, particularmente às crises políticas e sociais intensas, hoje parece haver abundância desse tipo de crises, no entanto isso pouco se reflete nas elaborações dos teóricos políticos. Seria, neste ponto, possível retomar a crítica feita por Leo Strauss à Ciência Política comportamentalista e aplicá-la hoje à Teoria Política. "Somente um grande tolo poderia chamar a nova Ciência Política de diabólica; ela não tem nenhum atributo peculiar dos anjos caídos. Não é sequer maquiavélica, os ensinamentos de Maquiavel eram refinados, sutis e vívidos. Nem é neroniana. Alguém poderia dizer que ela brinca enquanto Roma está em chamas. Mas ela está desculpada por dois motivos: ela não sabe que brinca e não sabe que Roma está em chamas" (STRAUSS, 1962, p. 327).

O liberalismo igualitário buscou construir uma justificação filosófica à existência do Welfare State e as possibilidades de um processo redistributivo no interior das economias capitalistas avançadas. $O$ vínculo entre a filosofia política igualitária e as políticas do Welfare State era tão forte que alguns teóricos chamavam o liberalismo igualitário de "liberalismo do Welfare State" e descreviam Rawls como oferecendo "uma apologia filosófica para um tipo igualitário de capitalismo de Welfare State". No entanto, este vínculo tem sido fortemente questionado; não é mais evidente que a implementação do liberalismo igualitário leve à construção de qualquer tipo de Welfare State. O próprio Rawls tem reconhecido as limitações do Welfare State para alcançar a igualdade liberal, mas infelizmente provendo meramente uma descrição de uma alternativa viável: uma democracia de proprietários. Em suma, os compromissos institucionais de liberalismo igualitário não têm estado à altura de seus desafios teóricos.

Para Kymlicka (2002, p. 92-93), uma das razões do acuamento das propostas dos liberais igualitários é que estes perderam a confiança na capacidade do Estado de prover justiça. A obra inicial de Rawls é do começo da década de 1970, quando o Welfare State era visto como essencialmente exitoso, e com resultados concretos em relação aos problemas da pobreza e da divisão de classes. No entanto, nas últimas décadas essa confiança tem desaparecido; a recessão do começo dos anos 1970, a crise do petróleo e o aumento dos déficits governamentais levam a pensar que as políticas de bem-estar eram insustentáveis. Paradoxalmente quando a necessidade de políticas ativas do Estado para combater as desigualdades na renda tem aumentado consideravelmente, as teorias liberais igualitárias parecem ter perdido, cada vez mais, a 
confiança na capacidade do Estado de remediálas, e suas propostas, como conseqüência, têm perdido o horizonte teórico.

Por outra parte, os termos dentro dos quais tem se desenvolvido o debate metodológico nos Estados Unidos e na Inglaterra têm levado autores como Skinner e Pocock a estabelecer uma conexão sistemática entre a construção de uma philosophia perennis e todas as visões filosóficas que buscam entender o vínculo existente entre os temas passados e presentes. As condições e pressupostos sob os quais esses autores desenvolveram sua crítica da forma tradicional de abordagem da história das idéias têm impedido de dar um passo decisivo para elaborar uma história filosófica da política. Sua contribuição de todas maneiras continua a ser inestimável (ROSANVALLON, 2001, p. 203).

Dessa forma, a abordagem proposta parece condenada a certo elemento despolitizador, por não conseguir distinguir entre o problema dos temas eternos da filosofia e as questões filosóficas e políticas relevantes do ponto de vista contemporâneo.

Para Rosanvallon, considerar o papel da teoria da política no momento atual nos deve levar a reconsiderar a relação entre trabalho intelectual e envolvimento político e cívico. A força da Teoria Política está relacionada com considerar a experiência acadêmica como parte integrante da experiência cívica. Isto deve levar a uma nova forma de compromisso político. Como conseqüência, o trabalho teórico deve ser uma parte fundamental do processo cívico. O conhecimento, dessa forma, deixa de ser uma atividade individual e passiva e se transforma numa forma de ação coletiva; o trabalho intelectual é per se uma forma de prática política. É uma forma de compressão política que, pela sua contribuição na elucidação das contradições, participa na tentativa de definir o que pertence propriamente ao domínio político. O que está no centro da discussão é a conexão entre erudição e compromisso; a Teoria Política deve ser capaz de forjar os instrumentos para analisar o mundo político e desenvolver as ferramentas do envolvimento prático. O objetivo é alcançar o ponto no qual a distinção entre conhecimento e ação desapareça. Isso significa participar no processo através do qual a sociedade deixa de estabelecer uma separação entre conhecimento da própria ação e conhecimento das causas que contribuem com ela (idem, p. 198-199).

Assim, o projeto de uma Teoria Política crítica, o que na presente perspectiva deve ser a própria definição de Teoria Política, deve estar baseado em uma tese central: implica em reelaborar a relação entre trabalho intelectual e prática política sobre novas bases, uma reelaboração que parta do pressuposto de um compromisso político da elaboração teórica com as necessidades sociais e particularmente com as necessidades dos setores subalternos.

Javier Amadeo (javier.amadeo@unifesp.br) é Doutor em Ciência Política pela Universidade de São Paulo (USP), Pós-Doutor no Departamento de História da mesma instituição e Professor de Teoria Política do Curso de Ciências Sociais da Universidade Federal de São Paulo (Unifesp).

\section{REFERÊNCIAS BIBLIOGRÁFICAS}

ALMOND, G. A. 1996. Political Science: The History of the Discipline. In: GOODIN, R. E. \& KLINGEMANN, H.-D. (eds.). A New Handbook of Political Science. Oxford: Oxford University.

ANDERSON, P. 1990. A Culture in Contraflow II. New Left Review, London, v. I, n. 180, Mar.Apr.

BALL, T. 2001. Discordant Voices: American Histories of Political Thought. In: CASTIGLIONE, D. \& HAMSPHER-MONK,
I. (eds.). The History of Political Thought in National Context. Cambridge: Cambridge University.

2004. Aonde vai a Teoria Política? Revista de Sociologia e Politica, Curitiba, n. 23, p. 9-22, nov. Disponível em: http:// www.scielo.br/scielo.php?script=sci_pdf \&pid=S0104-44782004000200003\&lng= pt\&nrm=iso\&tlng=pt. Acesso em: 15.jun.2011.

2007. Political Theory and Political Science: Can This Marriage Be Saved? Theoria: 
Journal of Social and Political Theory, Natal, v. 54, n. 113, p. 1-22, 2007, August.

BELAVAL, Y. 1981. La filosofía analítica. In: $L a$ filosofía en el siglo XX. Ciudad de México: Siglo XXI.

BEVIR, M. 2006. Political Studies as Narrative and Science, 1880-2000. Political Studies, v. 54 , n. 3, p. 583-606, Oct.

CASTIGLIONE, D. 1993. Historical Arguments in Political Theory. Political Theory Newsletter, Canberra, v. 5, n. 2, p. 89-109.

CASTIGLIONE, D. \& HAMPSHER-MONK, I. (eds.). 2001. The History of Political Thought in National Context. Cambridge: Cambridge University.

COLLINI, S. 2001. Postscript: Disciplines, Canons and Publics: the History of "the History of Political Thought" in Comparative Perspective. In: CASTIGLIONE, D. \& HAMPSHER-MONK, I. (eds.). The History of Political Thought in National Context. Cambridge: Cambridge University.

COLLINI, S.; WINCH, D. \& BURROW, J. 1987. La política, ciencia noble. Un estudio de la historia intelectual en el siglo XIX. Ciudad de México: Fondo de Cultura Económica.

DRYZEK, J. S.; HONIG, B. \& PHILLIPS, A. (eds.). 2006. The Oxford Handbook of Political Theory. Oxford: Oxford University.

DUNN, J. 1968. The Identity of the History of Ideas. Philosophy, London, v. 43, n. 164, p. 85-104, Apr.

DWORKIN , R. 2005. A virtude soberana. A teoria e a prática da igualdade. São Paulo: M. Fontes.

EASTON , D. 1953. The Political System. New York: Knopf.

1965. A System Analysis of Political Life. New York: Wiley.

FALCO, M. J. 1973. Truth and Meaning in Political Science: An Introduction to Political Inquiry. Columbus: C. E. Merrill.

FARR, J. 1995. Remembering the Revolution: Behavioralism in American Political Science. In: FARR, J.; DRYZEK, J. S. \& LEONARD, S. T. (eds.) Political Science in History.
Research Program and Political Traditions. Cambridge: Cambridge University.

GARGARELLA, R. 1999. Las teorías de la justicia después de Rawls. Un breve manual de filosofía política. Barcelona: Paidós.

GOODIN, R. E. \& HANS-DIETER, K. (eds.). 1996. A New Handbook of Political Science. Oxford: Oxford University.

GUNNELL, J. G. 1983. Political Theory: The Evolution of a Subfield. In: FINIFTER, A. W. (ed.). Political Science: The State of the Discipline. Washington (D. C.): American Political Science Association.

HAMPSHER-MONK, I. 1984. Political Languages in Time: The Work of J. G. A. Pocock. British Journal of Political Science, Cambridge, v. 14, n. 1, p. 89-116, Jan.

2001. The History of Political Thought and the Political History of the Thought. In: CASTIGLIONE, D. \& HAMSPHER-MONK, I. (eds.). The History of Political Thought in National Context. Cambridge: Cambridge University.

KOSELLECK, R. 2006. Futuro passado. Contribuição à semântica dos tempos históricos. Rio de Janeiro: Contraponto.

KYMLICKA, W. 2002. Contemporary Political Philosophy. An Introduction. Oxford: Oxford University.

LASLETT, P. (ed.). 1949. Patriarch a and Other Political Works of Sir Robert Filmer. Oxford: Garland.

1956. Introduction. In: (ed.). Philosophy, Politics and Society. Oxford: B. Blackwell. Disponível em: http:// www.questia.com/PM.qst?a=o\&d=1344695. Acesso em: 29.mar.2011.

(ed.). 1960. John Locke's Two Treatises of Government. Cambridge: Cambridge University.

MILLER, D. 1990. The Resurgence of Political Theory. Political Studies, v. 38, n. 3, p. 421437, Sept.

NEHAMAS, A. 1997. Trends in Recent American Philosophy. Daedalus, Cambridge (Mass.), v. 126, n. 1, p. 209-223, Winter. 
PAREK, B. 1996. Political Theory: Traditions in Political Philosophy. In: GOODIN, R. E. \& KLINGEMANN, H.-D. (eds.). A New Handbook of Political Science. Oxford: Oxford University.

POCOCK, J. G. A. 1962. The History of Political Thought: a Methodological Enquiry. In: LASLETT, P. \& RUNCIMAN, W. G. (eds.) Politics, Philosophy and Society. Oxford: Oxford University.

2003a. Linguagens do ideário político. São Paulo: USP.

2003b. The Maquiavellian Moment. Florentine Political Thought and the Atlantic Republican Tradition. Princeton: Princeton University.

2004. The Ancient Constitution and the Feudal Law. A Study of English Historical Thought in the Seventeenth Century. Cambridge: Cambridge University.

RAWLS, J. 1971. A Theory of Justice. Cambridge: Harvard University.

1988. The Priority of Right and Ideas of the Good. Philosophy \& Public Affairs, London, v. 17, n. 4, p. 251-276, Autumn.

1993. Political Liberalism. New York: Columbia University.

ROSANVALLON，P. 2001. Towards a Philosophical History of the Political. In: CASTIGLIONE, D. \& HAMSPHER-MONK, I. (eds.). The History of Political Thought in National Context. Cambridge: Cambridge University.

SILVA , R. 2009a. O novo historicismo na Ciência Política: um encontro entre duas tradições. Revista Brasileira de Ciência Política, Brasília, v. 1, p. 123-151, jan.-jun. Disponível em: http:/ /rbcp.unb.br/artigo_html.php?id=7. Acesso em: 15.jun.2011.

.2009b. História intelectual e Teoria Política. Revista de Sociologia e Política, Curitiba, v. 17, n. 34, p. 301-318, out. Disponível em: www.scielo.br/pdf/rsocp/v17n34/a20v17n34. pdf. Acesso em: 15.jun.2011.

SKINNER, Q. 1988. A Reply to My Critics. In: TULLY, J. (ed.). Meaning and Context: Quentin Skinner and his Critics. Cambridge: Cambridge University.

1989. Language and Political Change. In: BALL, T.; FARR, J. \& RUSSELL, H. L. (eds.). Political Innovation and Conceptual Change. Cambridge: Cambridge University.

1999. Liberdade antes do liberalismo. São Paulo: UNESP.

2002a. Meaning and Understanding in the History of Ideas. In: . Visions of Politics. V. I: Regarding Method. Cambridge: Cambridge University.

2002b. Interpretation and the Understand of Speech Acts. In:__. Visions of Politics. V. I: Regarding Method. Cambridge: Cambridge University.

2002c. Introduction: Seeing Things Their Way. In: ___ Visions of Politics. V. I: Regarding Method. Cambridge: Cambridge University.

2009. As fundações do pensamento politico moderno. São Paulo: Companhia das Letras.

STRAUSS , L. 1962. Epilogue. In: STORING, H. J. (ed.). Essay on the Scientific Study of Politics. New York: Holt, Rinehart \& Winston.

1988. What is Political Philosophy. In : . What is Political Philosophy and Other Studies. Chicago: University of Chicago.

VITA, A. 2000. A justiça igualitária e seus críticos. São Paulo: UNESP.

WOLIN, S. 2004. Politics and Vision. Continuity and Innovation in Western Political Thought. Princeton: Princeton University. 